\title{
Critical Consciousness: A Developmental Approach to Addressing Marginalization and Oppression
}

\author{
Matthew A. Diemer, ${ }^{1}$ Luke J. Rapa, ${ }^{2}$ Adam M. Voight, ${ }^{3}$ and Ellen H. McWhirter ${ }^{4}$ \\ ${ }^{1}$ University of Michigan, ${ }^{2}$ Michigan State University, ${ }^{3}$ Cleveland State University, and ${ }^{4}$ University of \\ Oregon
}

ABSTRACT-Grounded in the theory and pedagogy of Brazilian educator Paulo Freire, critical consciousness (CC) comprises components of critical reflection, critical motivation, and critical action. CC represents marginalized or oppressed people's analysis of societal inequities and their motivation and actions to redress such inequities. In this article, we introduce the theoretical underpinnings of $C C$, then look at the conceptualization and measurement of $C C$, and outline traditional and contemporary approaches to fostering $\mathrm{CC}$. We also summarize individual and collective outcomes associated with $\mathrm{CC}$ and offer suggestions for researchers and practitioners. Collectively, these insights suggest that $C C$ is an important developmental asset for marginalized youth and communities.

KEYWORDS—critical consciousness; marginalization; oppression; sociopolitical development

The concept of critical consciousness (CC), or conscientização, was developed by Brazilian educator Paulo Freire (1) as an approach to help rural Brazilian peasants learn to read the written word and read the world. For oppressed or marginalized people, Freire believed that developing literacy was intertwined

Thank you to Aixa Marchand for her helpful and insightful comments on this article. Drs. Matthew A. Diemer and Adam M. Voight were supported by a grant from the Spencer Foundation ("Critical social analysis among marginalized youth"). Note that Diemer and Rapa share first authorship of this paper, yet are listed alphabetically here.

Correspondence concerning this article should be addressed to Matthew A. Diemer, University of Michigan, Room 4120, School of Education Building, Ann Arbor, MI 48109; e-mail: diemerm@umich.edu.

(c) 2016 The Authors

Child Development Perspectives @ 2016 The Society for Research in Child Development DOI: $10.1111 /$ cdep.12193 with learning to critically "read" dehumanizing social conditions, because marginalization and oppression led people to believe that their voices and perspectives were irrelevant, that they were powerless, and that literacy was not necessary for "people like us."

Freire observed that as oppressed peoples' thinking about and understanding of their social conditions developed, their views of themselves in relation to society also developed. That is, as their thinking about social structures became more nuanced and complex, oppressed people became less constrained by their social conditions and, in turn, developed the agency and capacity to change these conditions, resolve developmental challenges, and determine their own lives. This transitive cycle of developing reflection and action is a central element of CC theory (1) because CC entails "learning to perceive social, political, and economic contradictions, and to take action against the oppressive elements of reality" (p. 35).

Contemporary formulations of CC focus on youth (ages 1222), are grounded in Freirean thought, and posit three core elements: critical reflection, critical motivation (or efficacy), and critical action $(2,3)$. Critical reflection refers to the process of learning to question social arrangements and structures that marginalize groups of people - "learning to see ... how history works, how received ways of thinking and feeling perpetuate existing structures of inequality" (4, p. 13). Critical motivation refers to the perceived capacity and commitment to address perceived injustices. Critical action refers to engaging individually or collectively to change perceived injustices (5). This perspective focuses on social stratification and discrimination to understand normative developmental processes and competencies among marginalized youth, consistent with classic (6) and contemporary scholarship (7) on development.

As an example of how CC is applied, consider a U.S. high school that suspends African American students disproportionately (see also 8). Students with higher levels of CC would be more likely to recognize that school disciplinary policies are 
being applied differently by race, have more agency to respond to this injustice, and be more likely to address inequitable suspension rates by, for example, joining a student group, protesting by walking out, or attending a school board meeting to call attention to the issue. Students with lower levels of CC would be more likely to fail to recognize the disproportionate disciplinary practices, ignore or minimize the underlying racism, or blame the African American students who are suspended. They would also be more likely to lack interest or feel powerless to do anything about the situation, or to avoid talking about or acknowledging the problem.

In this article, we look at how CC is conceptualized and measured, then review traditional and contemporary approaches to fostering CC. We also summarize outcomes associated with and impacts of CC at the individual and collective levels. We conclude by offering suggestions for research, practice, and policy. Collectively, these insights suggest that CC is an important developmental asset for marginalized youth and communities.

\section{CONCEPTUALIZING AND MEASURING CC}

Although CC has been of interest for decades, only recently have valid measures been developed (2), in part because conceptualizing and measuring $\mathrm{CC}$ is challenging. Freire did not provide a precise conceptual framework for CC, and modern conceptualizations have varied in their emphases on reflection, motivation, or action $(3,5)$. Indeed, the very term $C C$ may suggest misleadingly that CC is solely critical social analysis. Moreover, scholars sometimes interchange the terms $C C$, empowerment, and sociopolitical development (see 7 for a review).
Four recent quantitative measures of $\mathrm{CC}$ among marginalized youth help clarify these complexities: the Critical Consciousness Inventory (9), the Critical Consciousness Scale (10), the Measure of Adolescent Critical Consciousness (11), and the Sociopolitical Consciousness measure (12). Because others have addressed advances in conceptualizing and measuring CC (2), we provide a general review of features of these measures in Table 1.

The advantages of quantitative measurement include the capacity to assess the development of CC and its specific dimensions before and after an intervention, as well as easier administration and scoring. This allows researchers to identify how interventions might differentially enhance reflection, foster motivation and agency, or spur action. In contrast, a priori quantitative conceptualizations may overlook dimensions of CC that are not measured directly by that instrument. Similarly, marginalized youth may hold sociopolitical wisdom that Likert-type measurements fail to access (13).

\section{TRADITIONAL AND CONTEMPORARY APPROACHES TO FOSTERING CC}

Freire believed that CC could be developed through intervention. CC interventions feature collaborative small-group dialog and promote a shared sense of values and commitments among participants. Facilitators use Socratic questioning to discuss personal experiences of marginalization that connect youth to larger social structures and issues. These elements are intended to promote critical reflection, motivation, and action, and to foster a collective identity (often based on social identities) among participants, which is believed to reinforce the development of CC.

Table 1

Overview of Measures of Critical Consciousness.

\begin{tabular}{|c|c|c|c|c|}
\hline Scale & Items & Components/subscales & $\begin{array}{l}\text { Validation sample } \\
\text { and language }\end{array}$ & Scale foci \\
\hline $\begin{array}{l}\text { Critical } \\
\text { Consciousness } \\
\text { Inventory }\end{array}$ & $\begin{array}{l}\text { Nine items, } \\
\text { Guttman } \\
\text { Scaling }\end{array}$ & $\begin{array}{l}\text { Unidimensional. Critical consciousness } \\
\text { development level (stage model); scores reflect } \\
\text { "precritical," "beginning critical," "critical," } \\
\text { and "postcritical consciousness" stages. }\end{array}$ & $\begin{array}{l}\text { Diverse university } \\
\text { students. English. }\end{array}$ & $\begin{array}{l}\text { Socioeconomic and } \\
\text { racial/ethnic } \\
\text { inequities }\end{array}$ \\
\hline $\begin{array}{l}\text { Critical } \\
\text { Consciousness } \\
\text { Scale }\end{array}$ & $\begin{array}{l}22 \text { items, } \\
\text { Likert-type }\end{array}$ & $\begin{array}{l}\text { Three subscales: Critical Reflection } \\
\text { (egalitarianism and perceived inequality), } \\
\text { Critical Action (sociopolitical participation) }\end{array}$ & $\begin{array}{l}\text { Poor and working class } \\
\text { African American } \\
\text { urban youth. English. }\end{array}$ & $\begin{array}{l}\text { Socioeconomic, } \\
\text { racial/ethnic, and } \\
\text { gender inequities }\end{array}$ \\
\hline $\begin{array}{l}\text { Measure of } \\
\text { Adolescent } \\
\text { Critical } \\
\text { Consciousness }\end{array}$ & $\begin{array}{l}10 \text { items, } \\
\text { Likert-type }\end{array}$ & $\begin{array}{l}\text { Two subscales: Critical Motivation (commitment } \\
\text { and agency to make a difference), Critical } \\
\text { Action (sociopolitical participation) }\end{array}$ & $\begin{array}{l}\text { Latina/o high school } \\
\text { students. English and } \\
\text { Spanish. }\end{array}$ & $\begin{array}{l}\text { Socioeconomic and } \\
\text { racial/ethnic } \\
\text { inequities }\end{array}$ \\
\hline $\begin{array}{l}\text { Sociopolitical } \\
\text { Consciousness }\end{array}$ & $\begin{array}{l}35 \text { items, } \\
\text { Likert-type }\end{array}$ & $\begin{array}{l}\text { Seven subscales: Sociopolitical Awareness, } \\
\text { Global Belief in a Just World, Collective } \\
\text { Responsibility to the Poor, Equality and } \\
\text { Rights, Belief in Collective Action, Localized } \\
\text { Community Efficacy, Problem Solving Efficacy }\end{array}$ & $\begin{array}{l}\text { Salvadoran high school } \\
\text { students. Spanish. }\end{array}$ & Social inequities \\
\hline
\end{tabular}

Note. See Diemer et al. (2) for further detail about each of these measures. 
Next, we turn to Freire's seminal CC intervention, and we discuss contemporary interventions that aim to foster CC.

\section{Freire's Culture Circles}

Freire's approach to fostering CC entailed the use of culture circles in which participants collaborated on, talked about, and analyzed common situations or objects (e.g., a rendering of an indigenous hunter with a bow and arrow, culturally relevant objects for Freire's participants) to identify and build awareness of the conditions and causes of social, cultural, and political inequality (14). These culture circles were designed to help Brazilian peasants develop literacy skills while making them aware of sociocultural and sociopolitical marginalization and oppression - that is, to read the word while also reading the world.

\section{Contemporary Approaches}

Contemporary interventions supplement Freire's discussionoriented culture circles with more structured elements, such as youth participatory action research (yPAR, a collaborative process in which youth are trained to conduct research to inform community change; see 2 ), as well as with pedagogy that analyzes race-, class-, and gender-based inequities. For instance, in a year-long CC intervention that included yPAR and examined contemporary issues of power and oppression, urban high school students reflected critically and acted on contemporary issues as part of their English literature studies (15). Course reading lists were expanded beyond traditional texts (e.g., Beowulf and Hamlet) to include popular films, books, and hip-hop music with the goal of exploring how race, class, and culture shape students' experiences, and examining issues relevant to their lives (e.g., academic achievement in urban public schools). By participating in these activities throughout the school year, students had opportunities to reflect on societal inequities, develop agency to navigate and challenge the constraints they faced in their school and communities, and have a platform to advocate for change.

The Mexican-American Studies (MAS) program was implemented by the Tucson (Arizona) Unified School District and from approximately 2003 to 2010 interwove CC explicitly with the curriculum. This year-long social studies course focused on developing critical reflection using a pedagogy of authentic caring, engaging high school students in critiques of traditional curricula that excluded the experiences of people of color, and examining U.S. colonial history and legacy. MAS provided opportunities for students and teachers to discuss their experiences with racism and other forms of marginalization in their school, and linked these experiences to societal and institutional racism and exclusion through classroom discussion and yPAR (16). The MAS program also identified and drew on the funds of knowledge students had gained through their families, communities, and cultures (13).

In other interventions, students examine or create media to promote critical social analysis and motivation to change social inequities. For example, in the Young Warriors eight-session after-school intervention (17), African American male high schoolers engaged in discussions about racial and gender stereotypes and social forces conveyed through popular media (hiphop music videos, television shows, film), and critically analyzed how these aspects of mass media linked to broader societal inequities. Some CC-focused interventions couple yPAR with innovations such as Photovoice (which combines photography with dialog) to facilitate marginalized youth's critical analysis of and motivation to change their social conditions and structural constraints $(12,18)$.

CC interventions also target teachers who work with marginalized youth. A two-semester graduate seminar within the Critical Civic Inquiry project (which is designed to involve youth in efforts to change and improve schools) aimed to raise teachers' CC via training, readings, discussions, and observations (19). Specifically, middle-school teachers were taught to participate in critical dialog with their students about issues related to educational equity while examining race, culture, and societal inequities.

These interventions have raised participants' CC, but they are time and labor intensive. A brief, one-time field experiment also raised participants' CC (20). In this adapted values-affirmation intervention, ninth and tenth graders were guided to write about how CC-oriented values (e.g., values aligned with inequality, egalitarianism, or activism, such as speaking up when someone is teased or treated unfairly because of race) were meaningful to them, and write about acting out these values within their schools, neighborhoods, or communities. This brief intervention increased youth's critical motivation and academic achievement (20).

Although many programs assume that critical reflection is a precursor to action, fostering reflection alone may be of limited benefit. Interventions that produce only armchair activists are incomplete and less aligned with the core tenets of CC (3). Furthermore, acting collectively is believed to initiate critical reflection and kindle agency (1). Given the likely bidirectional nature of these processes, interventions to develop CC should intentionally foster engagement in action while developing critical reflection, critical motivation, and collective identity simultaneously.

\section{INDIVIDUAL AND COLLECTIVE IMPACTS OF CC}

CC can alter the developmental trajectories of marginalized youth (ages 12-22) who disproportionately experience oppressive social structures, including limited access to educational and health-related resources (6); it can also alter the communities in which those youth live. Specifically, CC may mitigate the degree to which these contextual barriers translate to less favorable educational and health-related outcomes.

In terms of individual outcomes, marginalized youth with higher levels of CC are more likely to have more optimal mental 
health (21), greater academic engagement and achievement (11, 16, 22), higher levels of enrollment in higher education (23), and more successful career development in adolescence (24-26). They are also more likely to attain higher paying and higher status occupations in adulthood (27), and make healthier sexual decisions (28). Furthermore, in a career intervention that was informed by CC, female survivors of domestic violence progressed further in their occupational goals than other survivors who took part in a traditional career intervention (29), although CC may have different meanings for adult female survivors of domestic violence than for marginalized youth.

The theoretical mechanisms that link the development of CC to these desirable outcomes include improved skills in strategic thinking and communication, increased social capital via relationships with fellow activists (30), a deeper understanding of structural barriers and more agency to negotiate them, as well as increasing capacity to resolve developmental challenges despite societal constraints (25). Similarly, in a study of Puerto Rican high school students living in urban areas (22), "a politicized understanding of power, inequality and historical processes ... actually involves the most disengaged students in a process of CC that can serve as a catalyst for entry into more mainstream mobility routes" (p. 88-89). These individual outcomes of CC may help counteract aggregated educational and health-related disparities.

In terms of collective or contextual outcomes, marginalized youth have led critical action, informed by critical reflection, to secure additional resources to improve school facilities (31) and implement school-based programs to prevent violence (32). They have also disrupted the tracking of English-language learners to courses not considered to be college-preparatory (33) and instituted policies to address racial achievement gaps (34). These outcomes of CC may help counteract structural barriers to the success and wellness of oppressed youth and young adults.

\section{LOOKING AHEAD: SUGGESTIONS FOR RESEARCH, PRACTICE, AND POLICY}

The field has not yet produced a coherent body of research on the ontogenesis of CC. The movement from a critical acceptance of the status quo to critical and liberating action to redress societal inequities shares an intellectual foundation $(1,5,17)$. The broader developmental and CC-oriented literatures (e.g., sociopolitical development theory; 17) suggest that developing CC entails mutual and continuous influence among the three CC components of reflection, motivation, and action, rather than progression through qualitatively distinct stages. Yet whether a particular component of CC is especially catalytic in fostering the development of CC over time, and whether particular contexts or experiences are important in fostering CC and other core developmental processes are unclear (2). A recent study complicates our understanding, finding that critical motivation did not mediate or moderate the hypothesized link between reflection and action, contrary to-yet not overturning - canonical scholarly notions (35). Similarly, different pedagogical approaches (e.g., progressive schools that emphasize analyzing and challenging inequities vs. no-excuses schools that emphasize the agency to negotiate structural constraints) appear to differentially foster marginalized youth's critical social analysis or agency, also complicating our understanding of how pedagogy fosters the development of CC (36).

CC also implies consciousness of injustice, but does it cover all types of injustice? Similar to multicultural competencies in clinical practice, one might be more critically conscious about race and socioeconomic status (e.g., by being attentive to raceor class-based health disparities) while being relatively unaware about gender and sexual identity (e.g., issues of equal access or inclusion). Similarly, the broader developmental literature makes clear the domain-specific nature of much of human development, so CC may best be conceived of as a domain-specific construct (2).

Our understanding of CC, marginalization, and privilege is enhanced by variations in the development of CC that are linked to the kinds of marginalization people experience. People may have different levels of CC about different kinds of social inequality (e.g., White women may have a greater consciousness of and motivation to change sexism than racism). Absent intervention, people may more readily develop CC about their social identities that are more marginalized. While CC was initially conceived as a process that operates only among oppressed or marginalized people, neither classification is a dichotomy-people have some social identities that are more privileged (e.g., male) and some that are more marginalized (e.g., Latino). This complicates simply classifying a person (or group) as marginalized or not because some of their social identities may be marginalized while others may not be.

Because CC was formulated as a developmental process among oppressed and marginalized people to address their own oppression (1), establishing CC as a construct among more privileged people may necessitate revising or expanding core tenets. Whether a more privileged person develops CC-or develops the capacity to act as an ally to more marginalized people-involves more than semantics. More privileged people would not develop CC about their own oppression (except when personal social identities that are more marginalized are involved), but rather about the oppression of others - and about how their own privilege is maintained through others' oppression.

This distinction calls into question whether more privileged people develop CC (and whether CC has a different meaning for them) or develop the ability to be allies to marginalized people. One scholar (37) suggested that more privileged people develop $\mathrm{CC}$ in the process of acting as allies to more marginalized people. Similarly, the classic Blue Eyes/Brown Eyes exercise (in which a teacher treated students with blue eyes as superior to those with brown eyes) illustrates how young White students developed an awareness of racism and its consequences. Indeed, 
a new measure has been developed to assess CC among more privileged college students based on the premise that $\mathrm{CC}$ applies to more privileged people, too (38). Finally, justice-focused training for teachers, counselors, and psychologists presumes that those with privilege can develop CC.

The degree to which CC is an individual versus a collective phenomenon is also unclear. Many interventions promoting CC are collective in nature because critically analyzing social issues and taking meaningful social action relies on dialog and collaboration - and may also require struggle and healing - with others who have common experiences with or shared perspectives about oppression (13). Low-income middle schoolers of color in the same educational setting tend to have similar orientations toward civic action, and settings with more engaged youth generally have more positive teacher-student relationships and fewer behavioral incidents $(39,40)$. Researchers should investigate the degree to which the development of CC is a collective process and outcome, and address concomitant implications for measurement. They should also apply mixed methods to measuring CC (2) to illuminate the individual versus collective dimensions of CC and illustrate interactions among its reflection, motivation, and action components. Finally, further scholarship (7) should continue to disentangle CC and analogous constructs, such as sociopolitical development and psychological empowerment.

\section{CONCLUSION}

CC has been called an antidote to oppression (17) because it provides marginalized youth with the awareness, motivation, and agency to identify, navigate, and challenge social and structural constraints. As such, CC may foster positive youth development despite constraints (6). New measures of CC provide tools to assess the specific dimensions of CC, gauge how well interventions promote $\mathrm{CC}$, and perhaps unify what have been fragmented approaches to conceptualizing and measuring CC. A variety of approaches have linked CC to adaptive developmental outcomes, suggesting that CC may be a developmental asset for marginalized youth and their communities. A coalescing literature suggests common elements of CC interventions, guiding how intervention programs should be designed. Although much remains to be discovered, this literature suggests conceptual and measurement strategies, intervention elements, and empirical links. We hope these advances foster the development, selfdetermination, and well-being of marginalized youth and communities.

\section{REFERENCES}

1. Freire, P. (2000). Pedagogy of the oppressed (30th anniversary ed). (M. Bergman Ramos, Trans.). New York, NY: Continuum.

2. Diemer, M. A., McWhirter, E., Ozer, E., \& Rapa, L. J. (2015). Advances in the conceptualization and measurement of critical consciousness. Urban Review, 47, 809-823. doi:10.1007/s11256015-0336-7

3. Watts, R. J., \& Hipolito-Delgado, C. (2015). Thinking ourselves to liberation? Advancing sociopolitical action in critical consciousness. Urban Review, 47, 847-867. doi:10.1007/s11256-015-0341-x

4. Hopper, K. (1999). John Berger and Erick Holtzman. Social Policy, $30,13-21$.

5. Watts, R. J., Diemer, M. A., \& Voight, A. M. (2011). Critical consciousness: Current status and future directions. In C. A. Flanagan \& B. D. Christens (Eds.), Youth civic development: Work at the cutting edge. New Directions for Child and Adolescent Development, 134, 43-57. doi:10.1002/cd.310

6. García Coll, C., Lamberty, G., Jenkins, R., Pipes McAdoo, H., Crnic, K., Wasik, B. H., \& Vázquez García, H. (1996). An integrative model for the study of developmental competencies in minority children. Child Development, 67, 1891-1914. doi:10.1111/j.14678624.1996.tb01834.x

7. Christens, B. D., Winn, L. T., \& Duke, A. M. (2016). Empowerment and critical consciousness: A conceptual cross-fertilization. Adolescent Research Review, 1, 15-27. doi:10.1007/s40894-015-0019-3

8. Shedd, C. (2015). Unequal city: Race, schools, and perceptions of injustice. New York, NY: Russell Sage Foundation.

9. Thomas, A. J., Barrie, R., Brunner, J., Clawson, A., Hewitt, A., Jeremie-Brink, G., \& Rowe-Johnson, M. (2014). Assessing critical consciousness in youth and young adults. Journal of Research on Adolescence, 24, 485-496. doi:10.1111/jora.12132

10. Diemer, M. A., Rapa, L. J., Park, C. J., \& Perry, J. C. (in press). Development and validation of the Critical Consciousness Scale. Youth \& Society. Advance online publication. doi:10.1177/ 0044118X14538289

11. McWhirter, E. H., \& McWhirter, B. T. (in press). Critical consciousness and vocational development among Latina/o high school youth: Initial development and testing of a measure. Journal of Career Assessment. Advance online publication doi:10.1177/1069072 715599535

12. Baker, A. M., \& Brookins, C. C. (2014). Toward the development of a measure of sociopolitical consciousness: Listening to the voices of Salvadoran youth. Journal of Community Psychology, 42, 10151032. doi:10.1002/jcop.21668

13. Sánchez Carmen, S. A., Domínguez, M., Greene, A. C., Mendoza, E., Fine, M., Neville, H. A., \& Gutiérrez, K. D. (2015). Revisiting the collective in critical consciousness: Diverse sociopolitical wisdoms and ontological healing in sociopolitical development. Urban Review, 47, 824-846. doi:10.1007/s11256-015-0338-5

14. Freire, P. (1973). Education for critical consciousness. New York, NY: Continuum.

15. Duncan-Andrade, J. M. R., \& Morrell, E. (2008). The art of critical pedagogy: Possibilities from moving theory to practice in urban schools. New York, NY: Peter Lang.

16. Cabrera, N. L., Milem, J. F., Jaquette, O., \& Marx, R. W. (2014). Missing the (student achievement) forest for all the (political) trees: Empiricism and the Mexican American Studies controversy in Tucson. American Educational Research Journal, 51, 1084-1118. doi:10.3102/0002831214553705

17. Watts, R. J., Griffith, D. M., \& Abdul-Adil, J. (1999). Sociopolitical development as an antidote for oppression-Theory and action. American Journal of Community Psychology, 27, 255-271. doi:10.1023/A:1022839818873

18. Carlson, E. D., Engbretson, J., \& Chamberlain, R. M. (2006). Photovoice as a social process of critical consciousness. Qualitative 
Health Research, 16, 836-852. doi:10.1177/1049732306287 525

19. Zion, S., Allen, C. D., \& Jean, C. (2015). Enacting a critical pedagogy, influencing teachers' sociopolitical development. Urban Review, 47, 914-933. doi:10.1007/s11256-015-0340-y

20. Rapa, L. J. (2016). Fostering marginalized youths' academic achievement and critical consciousness through a values-affirmation intervention. Unpublished doctoral dissertation, Department of Counseling, Educational Psychology, and Special Education. East Lansing, MI: Michigan State University.

21. Zimmerman, M. A., Ramírez-Valles, J., \& Maton, K. I. (1999). Resilience among urban African American male adolescents: A study of the protective effects of sociopolitical control on their mental health. American Journal of Community Psychology, 27, 733-751. doi:10.1023/A:1022205008237

22. Ramos-Zayas, A. Y. (2003). National performances: The politics of race, class and space in Puerto Rican Chicago. Chicago, IL: University of Chicago Press.

23. Rogers, J., \& Terriquez, V. (2013). Learning to lead: The impact of youth organizing on the educational and civic trajectories of lowincome youth. Los Angeles, CA: Institute for Democracy, Education, and Access.

24. Diemer, M. A., Wang, Q., Moore, T., Gregory, S. R., Hatcher, K. M., \& Voight, A. M. (2010). Sociopolitical development, work salience, and vocational expectations among low socioeconomic status African American, Latin American, and Asian youth. Developmental Psychology, 46, 619-635. doi:10.1037/a0017049

25. Luginbuhl, P. J., McWhirter, E. H., \& McWhirter, B. T. (2016). Sociopolitical development, autonomous motivation, and education outcomes among low income Latina/o adolescents. Journal of Latina/o Psychology, 4, 53-59. doi:10.1037/lat0000041

26. Olle, C. D., \& Fouad, N. A. (2015). Parental support, critical consciousness, and agency in career decision making for urban adolescents. Journal of Career Assessment, 23, 533-544. doi:10.1177/ 1069072714553074

27. Diemer, M. A. (2009). Pathways to occupational attainment among poor youth of color. The Counseling Psychologist, 37, 6-35. doi:10.1177/0011000007309858

28. Campbell, C., \& MacPhail, C. (2002). Peer education, gender and the development of critical consciousness: Participatory HIV prevention by South African youth. Social Science \& Medicine, 55, 331-345. doi:10.1016/S0277-9536(01)00289-1

29. Chronister, K. M., \& McWhirter, E. H. (2006). An experimental examination of two career interventions for battered women. Journal of Counseling Psychology, 53, 151-164. doi:10.1037/00220167.53.2.151

30. Kirshner, B. (2007). Introduction: Youth activism as a context for learning and development. American Behavioral Scientist, 51, 367379. doi:10.1177/0002764207306065

31. Shah, S., \& Mediratta, K. (2008). Negotiating reform: Young people's leadership in the educational arena. New Directions for Youth Development, 117, 43-59. doi:10.1002/yd.246

32. Voight, A. (2015). Student voice for school-climate improvement: A case study of an urban middle school. Journal of Community and Applied Social Psychology, 25, 310-326. doi:10.1002/casp. 2216

33. Speer, P. W. (2008). Social power and forms of change: Implications for psychopolitical validity. Journal of Community Psychology, 36, 199-213. doi:10.1002/jcop.20231

34. Christens, B., \& Kirshner, B. (2011). Taking stock of youth organizing: An interdisciplinary perspective. New Directions for Child and Adolescent Development, 134, 27-41. doi:10.1002/ cd.309

35. Diemer, M. A., \& Rapa, L. J. (2016). Unraveling the complexity of critical consciousness, political efficacy, and political action among marginalized adolescents. Child Development, 87, 221-238. doi:10.1111/cdev.12446

36. Seider, S., Graves, D., Clark, S., Soutter, M., El-Amin, A., Tamerat, J., ... Sklarwitz, S. (in press). Preparing adolescents attending progressive and no excuses urban charter high schools to analyze, navigate, and challenge race and class inequality. Teachers College Record. Advance online publication.

37. Watts, R. J., Williams, N. C., \& Jagers, R. J. (2003). Sociopolitical development. American Journal of Community Psychology, 31, 185-194. doi:10.1023/A:1023091024140

38. Shin, R. Q., Ezeofor, I., Smith, L. C., Welch, J. C., \& Goodrich, K. M. (2016). The development and validation of the contemporary critical consciousness measure. Journal of Counseling Psychology, 63, 210-223. doi:10.1037/cou0000137

39. Geller, J. D., Voight, A., Wegman, H., \& Nation, M. (2013). How do varying types of youth civic engagement relate to perceptions of school climate? Applied Developmental Science, 17, 135-147. doi:10.1080/10888691.2013.804377

40. Karakos, H., Voight, A., Geller, J., Nation, M., \& Nixon, C. (2016). Student civic engagement and school climate: Associations at multiple levels of the school ecology. Journal of Community Psychology, 44, 166-181. doi:10.1002/jcop.21748 